\section{UN DIÁLOGO EN TORNO A LA CRISIS DEL POSITIVISMO JURÍDICO Y EL RESURGIR DEL PLURALISMO JURÍDICO*}

\author{
A DIALOGUE ABOUT LEGAL POSITIVISM \\ CRISIS AND THE RESURGENCE OF LEGAL \\ PLURALISM
}

UM DIÁLOGO SOBRE A CRISE DO POSITIVISMO
JURÍDICO E O RESSURGIMENTO DO
PLURALISMO JURÍDICO

\section{RESUMEN}

La tensión entre el positivismo jurídico y el pluralismo jurídico permite en el presente trabajo establecer un diálogo en torno a la "crisis del positivismo jurídico y el resurgir del pluralismo jurídico", en otras palabras, no todos han prestado atención al desarrollo de carácter jurídico, cultural y político, por mencionar algunos aspectos, respecto a las coincidencias y tensiones que se presentan entre el positivismo jurídico y el pluralismo jurídico, lo que implica iniciarse en el tema para lograr expresar una postura con sentido científico y argumentativo.

Para ello se requiere de un gran bagaje de teoría de derecho y filosofía de derecho, lo que hace necesario acompañar un número de trabajos que permiten un acercamiento al tema, en el caso particular,
* Artículo de reflexión.

a. Abogado Universidad Libre, maestría derecho penal y criminología Universidad Libre, maestría estudios político Universidad Javeriana, docente investigador universidades Colegio Mayor de Cundinamarca y Universidad Gran Colombia, catedrático Universidad Libre. Ponente nacional e internacional, autor de varios libros referidos a derecho penal y derechos humanos, además artículos en varias revistas universitarias.
Over Humberto Serrano Suárez ${ }^{\mathrm{a}}$ overserrano@gmail.com

Fecha de recepción: 15 de Febrero 2015 Fecha de revisión:20 de Febrero 2015 Fecha de aceptación: 15 de Marzo 2015
MISIÓN JURÍDICA

Revista de Derecho y Ciencias Sociales Bogotá, D.C. (Colombia)

Colaboradores Externos Internacionales Núm. 8, Año 2015

enero-junio, pp. 171-187.

ISSN 1794-600X 
abrir un puerta de interacción con quienes conocen más de cerca y profundidad la temática.

Se recurre a varios autores para hacer un ejercicio comparativo académico tangencial al mismo. Pero ante todo visibilizar autores colombianos que aportan hacia el fortalecimiento del pluralismo jurídico.

\section{PALABRAS CLAVES}

Positivismo jurídico, pluralismo jurídico, teoría de derecho, filosofía de derecho, autores colombianos, trabajo analítico, deductivo o inductivo, teórico crítico.

\begin{abstract}
The tension between legal positivism and legal pluralism in this paper allows a dialogue about the "crisis of legal positivism and the resurgence of legal pluralism". In other words, not everyone has been paying attention to the development of legal, cultural and politic matters, to mention some aspects regarding to the coincidences and tensions that take place between legal positivism and legal pluralism which implies to initiate in the topic and get to express a stance with scientific and argumentative sense.
\end{abstract}

To achieve this a great background of theory of law and philosophy of law, which is necessary to accompany a number of works that grant an approach to the subject, in this particular case, it opens a door to interact with those who know the topic more closely and deeply.

Hence we use several authors for a comparative academic exercise tangential to it. But, above all, we make visible Colombian authors that contribute to the strengthening of legal pluralism.

\section{KEYWORDS}

Legal positivism, legal pluralism, theory of law, philosophy of law, Colombian authors, analytical, deductive or inductive work, critical theorist.

\section{RESUMO}

A tensão entre o positivismo jurídico e o pluralismo jurídico, neste estudo, permite estabelecer um diálogo sobre a "crise do positivismo jurídico ao ressurgir do pluralismo jurídico", em outras palavras, nem todos têm dado atenção ao desenvolvimento de menção legal , cultural e político alguns aspectos relativos as semelhanças e as tensões que surgem entre o positivismo jurídico e o pluralismo jurídico , o que implica introdução ao tema para expressar uma posição com sentido científico e argumentativo.

Isto implica numa rica bagagem da teoria do Direito e da filosofia do Direito, tornando-se necessário acompanhar um número de trabalhos que viabilizem uma abordagem sobre o tema; como no caso particular, abrir uma porta de interação com aqueles que conhecem mais de perto e com profundidade a temática.

Por isso, vamos recorrer a vários autores para fazer um tangencial comparativo acadêmico do tema, mas, acima de tudo, apresentaremos os autores colombianos que abordam o fortalecimento do pluralismo jurídico.

\section{PALAVRAS-CHAVE}

Positivismo jurídico, pluralismo jurídico, teoria do direito, filosofia do direito, autores colombianos, trabalho analítico, dedutivo ou indutivo, teórico crítico.

\section{INTRODUCCIÓN}

El presente trabajo se circunscribe a realizar un ejercicio de comentario y reseña sobre apartes de trabajos referidos tanto al positivismo como al pluralismo jurídico, que en forma descriptiva permita a los neófitos tener una posibilidad de ingresar al marco de la discusión planteada con una serie de bases que permitan entender y plantear puntos de vista respecto al positivismo y el pluralismo jurídico. Esto con el fin de conducir a los lectores a elaborar un trabajo analítico, deductivo o inductivo, teórico crítico, con fundamento en lo plasmado en el presente estudio. En síntesis, constituye un estado del arte que motiva a ir en búsqueda de un trabajo que lo complemente, con un número importante de fuentes bibliográficas.

\section{PROBLEMA}

No todos han prestado atención al desarrollo de carácter jurídico, cultural y político, por 
mencionar algunos aspectos, respecto a las coincidencias y tensiones que se presentan entre el positivismo jurídico y el pluralismo jurídico, lo que implica un esfuerzo intelectual analítico. También iniciarse en el tema, para no sucumbir en la especulación sin lograr expresar con sentido científico, y argumentativo, una postura, es decir: El problema, que se deja en clave de inquietud, tiende a ser resuelto, con notas descriptivas de quienes han trasegado el camino de crisis del positivismo jurídico y el resurgir del pluralismo jurídico.

\section{METODOLOGÍA}

Se opta por la consulta de doctrina de orden socio jurídico e histórico, tanto autores colombianos como de tratadistas internacionales, construyendo una línea de pensamiento entre crisis y resurgimiento en la tensión planteada entre positivismo jurídico y pluralismo jurídico. Metodología cercana al análisis cualitativo.

\section{RESULTADOS Y CONTENIDO}

\section{VOCES RESPECTO AL POSITIVISMO JURÍDICO ACIERTOS Y DESACIERTOS}

Diego Eduardo López Medina ${ }^{1}$ refiere al positivismo jurídico y la facilidad en que se puede particularizar, atendiendo al origen de las normas legales, o disertar de un tema común. A modo de cita "la defensa de los derechos humanos" pero desde un "punto de vista" local-, bien sea explicando por qué su "realidad" o su "cultura" enclavan modificaciones significativas a la comprensión estandarizada y transnacional del tema.

Además de lo anterior López Medina afirma:

(...) la mutación que se hizo de la teoría pura del derecho de Hans Kelsen no obedece a características sociológicas de la población colombiana o de la profesión jurídica, sino el dominio teórico previo que concentró, desde la

1 DIEGO EDUARDO LÓPEZ MEDINA "Teoría impura del derecho - La transformación de la cultura jurídica latinoamericana" Legis, tercera edición 2005, página 10. expedición de los códigos nacionales, el positivismo jurídico francés del siglo XIX².

Al referirse a las obras de KELSEN y HART, López Medina percibe una ocupación del espacio común del positivismo jurídico que, en últimas, es enfrentada en la jurisprudencia local mucho más allá de las diferencias de detalle. Ello para decir que, de conformidad a los usos que se hacen de tales teorías en la jurisprudencia regional, HART y KELSEN se perciben como tótems teóricos de un serio conflicto jurídico, no menos que las diferencias internas de matices fácilmente aceptables dentro del campo positivista.

Observa que el neoclasicismo llegó a ser hegemónico porque su estrategia, bien coordinada, conllevó a que se orientara directamente a las practicas del profesional del derecho poco interesado en los detalles de la teoría legal (clasicismo), no obstante, al mismo tiempo, brindaba una versión muy sofisticada y completa de los principales artículos de fe del positivismo jurídico (kelsenianismo).

Advierte el autor López Medina que

La cultura jurídica colombiana y sus jueces retienen dentro de su ejercicio profesional gran parte de la concepción clásica del derecho. El derecho codificado y legislado, por lo tanto, sigue siendo el ideal de legalidad propio del clasicismo. Desde la facultad de derecho se forman las bases de una teoría implícita construida con pedazos de clasicismo prekelseniano y adosada con elementos de positivismo kelseniano ${ }^{3}$.

Entre tanto Antonio Carlos Wolkmer ${ }^{4}$, indica, siguiendo sus palabras, que la propuesta normativista de Kelsen, visto como el máximo exponente del formalismo jurídico contemporáneo en Occidente, concuerda con un período mediado de dos grandes guerras caracterizado por depresión económica, crisis y la renovación del capitalismo, así como las implementaciones tecnocráticas y el crecimiento

2 Ibídem páginas 19, 35, 135, 449

3 DIEGO EDUARDO LOPEZ MEDINA, Op. cit. p.10 ss.

4 ANTONIO CARLOS WOLKMER "Pluralismo Jurídico Fundamentos de una nueva cultura del Derecho" editorial MAD 2006, España, página 65. 
organizado de las fuerzas productivas bajo el intervencionismo estatal ${ }^{5}$.

De otra parte ANTONIO CARLOS WOLKMER frente a la propuesta de un nuevo pluralismo jurídico (designado comunitario -participativo) configurado a través de un espacio público abierto y compartido democráticamente, privilegia la participación directa de agentes sociales en la regulación de las instituciones claves de la sociedad, lo que brinda la posibilidad que el proceso histórico se encamine por voluntad y bajo el control de las bases comunitarias. Es reiterativo, en esa tendencia, la propensión de ver el Derecho como fenómeno resultante de relaciones sociales y valoraciones deseadas, así como comprobar cómo se instaura otra legalidad a partir de la multiplicidad de fuentes normativas sin ser precisamente estatales. Destaca una legitimidad basada en las "justas" exigencias fundamentales de sujetos, y, finalmente, aborda la institución de la sociedad como una estructura descentralizada, pluralista y participativa ${ }^{6}$ que permite pensar que el autor llega al pluralismo jurídico. Es importante revisar, a partir de su mirada, cómo se alcanza una participación directa de agentes sociales en la regulación de las instituciones en un contexto simultáneo de tiempo y espacio.

Señala dos estrategias esenciales dirigidas a la producción legal emergente, ante la necesidad de diseñar los medios de superación del paradigma jurídico materializado en el Estado y de establecer el proyecto de un ordenamiento descentralizado y espontáneo, que nazca de la propia sociedad, fundado en la pluralidad de necesidades básicas y en el consenso de las diferencias. Dichas destrezas son: (i) Prácticas o mecanismos legales institucionales, de producción alternativa, existentes dentro del Derecho positivo oficial del Estado. (ii) Prácticas o mecanismos legales no institucionales de producción alternativa, fuera de la órbita del Derecho estatal positivo ${ }^{7}$.

A la cultura legal - estatal se le contrapone un modelo de pluralismo concebido a partir de los siguientes elementos: otro modo de entender la racionalidad; otra manera de comprender la ética a través del flujo político y jurídico de nuevos

5 Ibídem páginas 65 y 66.

6 Ibídem página 81.

7 Ibídem página 250 y 251. sujetos - los colectivos; por las nuevas necesidades - y de unos derechos construidos por el proceso histórico; y, finalmente, por la reordenación de la sociedad civil - el cambio normativo del centro hacia la periferia, del Estado hacia la sociedad, de la ley hacia los acuerdos, arreglos y negociaciones -. Se trata de la dinámica interactiva de un espacio público abierto, democrático y compartido ${ }^{8}$.

WOLKMER explica, respecto a la ideología del positivismo jurídico, revelarse a través de un riguroso formalismo normativista, que cambia en un genuino producto de la sociedad burguesa sólidamente edificada. Dicho formalismo, señala, cubre los origines sociales y económicos de la estructura de poder, lo que permite armonizar las relaciones entre capital y trabajo eternizando, mediante las reglas de control, el "statu quo" dominante ${ }^{9}$.

Considera no pretensioso subrayar que la moderna juridicidad resultante del iluminismo político, que pretende formar un derecho justo e igualitario:

(...) tuvo como exigencia la universalidad de la dignidad y de los derechos humanos, la solidaridad, la división de los poderes, la participación democrática y la liberación del hombre. Entre tanto, el iluminismo técnico científico, que hizo posible el dominio de la naturaleza, fracasó por no haber logrado la realización del hombre y el pleno dominio de sus instituciones sociales, estatales, morales y jurídicas.

(...) el iluminismo técnico -científico se desarrolló como forma instrumental racionalizada orientada hacia la alienación, represión y deshumanización, el saber jurídico, incrustado en la lógica de postulados empíricos, no fue capaz de realizar la emancipación y la liberación del hombre ${ }^{10}$.

En su entender, la estructura normativista del moderno Derecho positivo estatal es ineficaz y no responde al universo complejo y dinámico de las actuales sociedades de masas, que transitan por nuevas formas de producción

8 Ibídem página 308.

9 ANTONIO CARLOS WOLKMER" Pluralismo jurídico movimiento sociales y prácticas alternativas", http://ilsa.org.co:81/biblioteca/ dwnlds/od/elotrdr007/elotrdr007-02.pdf, El otro Derecho, numero 7 de 1991, Ilsa Bogotá. página 31, consultado 11 de noviembre de 2014.

10 Ibídem página 32. 
del capital, profundas contradicciones sociales, inestabilidades continuadas que muestran crisis de legitimidad, producción y aplicación de la justicia ${ }^{11}$. Visto de otra manera, percibe configurarse en el espacio de un pluralismo legal la existencia de amplios grupos sociales institucionalizados, capaces de elaborar y aplicar sus propias disposiciones normativas, señalando: las corporaciones de clase, asociaciones profesionales, consejos de fábrica, sindicatos, cooperativas, agremiaciones deportivas y religiosas, fundaciones educativas y culturales, entre otras. A su vez establece que cada uno de esos grupos, libremente organizados, exhiben un Derecho "interno", "institucional", "informal" y/o "espontaneo", paralelo e independiente del Estado; códigos oficiales, legislaciones elaboradas por las élites dominantes y por jueces en los tribunales estatales ${ }^{12}$.

Por otra parte, BONILLA considera que el positivismo se encaminó en procura de una justificación racional del sistema jurídico, implementando criterios de identificación distantes de las demás ciencias sociales, con ausencia de fundamentos de contenido moral. Percibe que el paradigma escrutaba describir el funcionamiento del sistema jurídico en lo descriptivo, desconociendo formas de valoración ajena al propio sistema. Lo que explica por qué los positivistas intentan hallar la estructura misma del sistema jurídico mediante un proceso de racionalización. Tal situación implica el problema de la validez, extraño a referencias de contenidos materiales unilaterales determinados, concibiendo la dicotomía entre las categorías del deber ser y el ser ${ }^{13}$.

BONILLA, siguiendo a CARLOS MASSINI, establece que la principal crítica al paradigma en estudio, y posible causal de su crisis, está dada. Consiste en que el referente teórico no se puede adaptar a cualquier justificación que facilite amparar los intereses políticos del momento, lo que implica un único y especifico contenido valorativo idealista ante el hecho de que el ordenamiento jurídico exista con independencia

11 Ibídem página 32.

12 Ibídem página 43.

13 JULIÁN DARÍO BONILLA MONTENEGRO “Los paradigmas en la teoría jurídica. Transformaciones acerca de la interpretación sobre lo que es el derecho". Revista Misión jurídica, número 3 enero- diciembre de 2010, Universidad Colegio Mayor de Cundinamarca, páginas 103 y 104. de la forma de control del poder político, vigente a su parecer ${ }^{14}$.

El paradigma crítico se caracteriza porque él no busca estudiar la validez del sistema jurídico: es a través de diversos autores que trata de encontrar respuesta a la pregunta sobre el porqué el derecho. Para tratar de resolver esta inquietud vemos que se presentan diversos puntos de vista como la negación del derecho, la existencia de un infra derecho; que dentro de una misma sociedad se presenten diferentes formas jurídicas, o que el derecho necesite siempre una forma de argumentación para poder solucionar los casos de acuerdo a la ley ${ }^{15}$.

Conforme a lo dicho, BONILLA encuentra que el paradigma crítico se caracteriza por la búsqueda de fórmulas que pretenden el cambio del funcionamiento actual del Derecho, negando que deban existir conceptos de validez, a través de conceptos jurídicos básicos: los sujetos jurídicos que interactúan, problemas políticos, de interpretación o descripción general del Derecho, bien del sistema jurídico o los derechos alternativos ${ }^{16}$.

CARRILLO, al escribir sobre "el problema de la obediencia y la validez del derecho"17, subraya que es un aspecto central de la teoría positivista cómo fundamentar la obediencia del Derecho en algo distinto de la fuerza bruta, encontrando esto posible sólo si se puede distinguir el Derecho del poder. Para ello sostiene que con el iusnaturalismo la obediencia y la validez del derecho se aseguran por referencia a ciertos valores superiores (razón) o supra históricos (Dios).

Se advierte, siguiendo a ORTEGA, que al desconectar el Derecho puesto (positivo) de la moral, el positivismo jurídico debe hallar fundamento de validez en un criterio distinto al derecho ideal (natural), un criterio fáctico (el poder) más que jurídico. Señala que el

14 Ibídem página 104.

15 Ibídem página 111

16 Ibídem página 115

17 CARRILLO DE LA ROSA, Yesid "La inclusión de la moral en el derecho y la encrucijada actual del positivismo jurídico, revista Diálogos de Saberes, Bogotá. Universidad Libre nro. 31, julio diciembre de 2009. 
positivismo formalista (exégesis francesa y la jurisprudencia de conceptos), resuelve el asunto apelando a la noción de soberanía de la ley, además de considerar que el derecho positivo no reflejaría el capricho y arbitrariedad del poder, sino una voluntad objetiva y justa ${ }^{18}$ que se expresa en forma clara y completa en la ley, por tanto, en su criterio, lo mejor es someterse al dictado de la autoridad soberana. No obstante, revela críticas de las concepciones socialistas del Derecho como la ausencia de neutralidad e imparcialidad de la norma frente a intereses sociales, relaciones de poder y las objeciones de las corrientes sociológicas que marcan no sólo la inoperancia y la insuficiencia del derecho frente a la realidad social cambiante, sino la existencia de lagunas y contradicciones en el sistema de Derecho. Tal situación torna insostenible el positivismo formalista y da paso a un positivismo sociológico o anti formalista, que si bien, en criterio de CARRILLO, sigue sosteniendo que el derecho es la ley (forma) esta es portadora de un contenido (valores, fines, propósitos) que debe ser descubierto por quien aplica el derecho.

En tal orden de ideas, acompañado del discurso de ORTEGA, predica que sus consideraciones se enfocan en la búsqueda de un método jurídico racional que garantice la interpretación correcta de la ley, según la voluntad o intención del legislador. Sin embargo, advierte que dichas críticas anti formalistas conducen al surgimiento de tendencias escépticas, más cuando se insinúan revelaciones críticas de las concepciones socialistas del Derecho ante una posible confrontación de un orden de derecha, (Escuela libre del Derecho y el Realismo jurídico norteamericano), que desconocen el aspecto normativo del Derecho y, a otras, que priorizan el aspecto fáctico. Cita el caso de la primera jurisprudencia analítica (Bentham y Austin) ${ }^{19}$ que identifica el Derecho con lo que ordena el soberano. Para Austin, comenta, existe una obligación si existe una norma y una norma si hay un mandato; el mandato es la expresión de un soberano que habitualmente es obedecido, y que respalda su querer con una sanción ${ }^{20}$, como

18 SEGURA ORTEGA, MANUEL. "La racionalidad jurídica". Madrid: editorial Tecnos, 1998, $p 30$.

19 Confrontar las cinco diferencias entre BenthamYAustin file:///C:/Users/investigaciones.dere/Downloads/Dialnet-Cinc oDiferenciasEntreBenthamYAustin-1985343.pdf, bajado 11 de marzo de 2015.

20 AUSTIN, Jonn, "la delimitación del ámbito de la teoría del es el caso del asaltante que ordena a su víctima entregarle el bolso bajo la amenaza de causarle un $\mathrm{mal}^{21}$.

CARRILLO aclara que la norma fundamental kelseniana pretende superar esta dificultad apelando a un criterio jurídico. En otras palabras expresa que, para Kelsen, la validez de una norma no puede hallarse en un pacto o contrato social, ni en la mera constatación del hecho de que quien emitió la orden es un soberano, sino en otra norma. Ello es, en un deber ser. El propósito de la Teoría Pura del Derecho, afirma, es el de describir los sistemas jurídicos positivos ${ }^{22}$, independiente de toda consideración axiológica o fáctica; de allí su carácter universal y objetivista ${ }^{23}$. Esta ciencia normativa, en su entender, debe facilitar el paso de una multiplicidad de normas heterogéneas (Constitución, leyes, decretos, etc.), a un sistema jurídico coherente y unitario, según Kelsen. Concluye que la noción de sistema jurídico, por una parte, posibilita el conocimiento del Derecho como un todo unitario, completo y coherente (dimensión lógico - epistemológica) y por otra, le otorga validez a una norma en particular y define su naturaleza, y su estatuto ontológico ${ }^{24}$.

El autor explica que Kelsen distingue entre sistema nomo - estático y sistema nomo dinámico, para decir que en el primero, en el que incluye al iusnaturalismo, la validez de la norma viene dada por el contenido de ésta, que puede subsumirse o deducirse de otras normas hasta llegar a la norma básica que fundamenta todo el sistema; por el contrario, en los sistemas normativos dinámicos, como el Derecho, las normas pueden tener el contenido moral que quieran pero valen si han sido autorizadas o promulgadas por el órgano competente conforme a su procedimiento prescrito por una norma superior y anterior ${ }^{25}$.

derecho". En: CASANOVAS, Pompeu y otros. El ámbito de lo jurídico, lecturas del pensamiento jurídico contemporáneo, editorial Crítica, 1994.p 182.

21 HARTH. el concepto de derecho, Traducción de Genaro R. Carrió, Buenos Aires: Abeledo - Perrot, 2004, p.8

22 KELSEN, $H$ "Teoría pura del derecho. Introducción a la ciencia del derecho". Novena edición, Traducción de Moisés Nilve, eudeba editorial universitaria de Buenos Aires, 1970, p 15.

23 KELSEN, H. "Teoría pura del derecho". Grupo editorial Éxodo, México D. F, 2006, pp21 y 108.

24 CARRILLO DE LA ROSA, Yesid. Temas y problemas de la filosofía del derecho. Ediciones Doctrina y Ley, Bogotá D C., 2008. pp 270 ss

25 CARRILLO DE LA ROSA, Yesid, Temas y problemas de la 
Según CARRILLO, Kelsen considera, con arreglo a la clasificación anterior, que las fuentes del Derecho se encuentran jerárquicamente subordinadas en torno de una fuente suprema que atribuye directa o indirectamente carácter jurídico a todo el conjunto de normas y que él llama: la norma fundamental. Indica el autor que esta no sólo permite otorgarle validez a la primera norma jurídica del sistema (la Constitución), sino también interpreta la norma como objetivamente válida, independiente de las relaciones de fuerza explicables causalmente, pues ella no ha sido dictada por algún legislador humano o divino, es una hipótesis básica de la que deriva la validez de la Constitución y las demás normas ${ }^{26}$. Subraya que la norma fundamental tuvo muchas variaciones y muchas críticas $^{27}$, especialmente el carácter no normativo de la norma fundamental, pues si fuese norma debería estar fundamentada a su vez en otra norma que estaría a su vez fundamentada en otra norma en un regreso infinito. Aprecia que, si únicamente esta norma tiene un carácter supra positivo, puede operar como punto de cierre del sistema jurídico. Por tanto considera, al no estar la norma fundamental apoyada en ninguna otra instancia, que se hallaría por fuera del sistema y no tendría ni el carácter de norma ni de jurídica ${ }^{28}$. Percibe, entonces, que la norma fundamental no es norma ni jurídica, no obstante, sin ella no operaría la traducción de los actos subjetivos del poder al Derecho, el paso de la mera causalidad (ser) a normatividad (deber ser), y por consiguiente, la transmutación de la fuerza descarnada a la racionalidad del derecho.

Asegura CARRILLO que Kelsen nunca pudo dar cuenta de la última norma fundamental que cierra y dota de unidad al sistema y da cuenta de la validez de las normas que la componen. Será la teoría de HART ${ }^{29}$ la que resuelve este problema para la concepción del Derecho (sistema jurídico) según el positivismo jurídico. Para HART indica, es claro que la metáfora del asaltante y el asaltado

\footnotetext{
filosofía del derecho. Ediciones Doctrina y ley, Bogotá D.C., 2008 SORIANO, Ramón. Compendio de teoría general del derecho, Ariel. Derecho, Barcelona, 2a edición, 1993, p. 122, y MARTíNEZ ROLDÁN, Luis y otro. Curso de teoría del derecho y metodología jurídica, editorial Ariel, S.A 1994, p 87 y KELSEN, H. Teoría pura del derecho, op, cit., PP. $109-110$.

26 KELSEN, H. "Teoría pura del derecho" op. Cit., p. 111-112 y sS. 27 CARRILLO DE LA ROSA, Yesid. Op .cit

28 BASTIDAS F, $X, O p$, cit. P 87

29 HARTH. el concepto de derecho, Traducción de Genaro R.
} Carrió, Buenos Aires: Abeledo - Perrot, 2004 no permite comprender la idea de obligación, pues quien accede a las pretensiones del asaltante "se vio obligado" a ello, pero no puede decir que "tenía la obligación"; para que se pueda hablar de obligación es fundamental que se hable de reglas sociales, porque es en virtud de éstas que un comportamiento es asumido como modelo de conducta y hace que un caso particular quede cobijado por ella. Las reglas se caracterizan porque, a diferencia de los mandatos, pueden ser advertidas desde un observador que no las acepta (punto de vista externo) o por un miembro del grupo (participante) que las acepta y las usa como guía de conducta (punto de vista interno); los enunciados que realice el observador se denominan enunciados externos y los que realice el participante enunciados internos ${ }^{30}$.

Con fundamento en HART, CARRILLO refiere que no es posible hablar de sistema jurídico si sólo hay normas que imponen deberes y obligaciones (reglas primarias) teniendo como consecuencia:

Una sociedad primitiva en la que sólo existan reglas primarias adolecería de varios defectos: uno de ellos sería el de la falta de certeza respecto al Derecho valido.

Otro defecto sería el carácter estático de las reglas, debido a que no habría posibilidad de llevar acabo un cambio deliberado de tales reglas.

La ineficacia de las normas (difusa presión social), pues en caso de violación de éstas no habría manera de resolver las disputas ${ }^{31}$.

La existencia de un sistema jurídico moderno presupone la presencia no sólo de reglas primarias, sino también de reglas secundarias. Las primarias se ocupan de las acciones que los individuos deben o no ejecutar; las secundarias de las reglas primarias y cumplen respecto de ellas

\section{Ibídem.}

31 Consultar CARRILLO DE LA ROSA YESID "La inclusión de la moral en el derecho y la encrucijada actual del positivismo jurídico, revista Diálogos de Saberes, Bogotá. Universidad Libre nro. 31, julio - diciembre de 2009. Además, CARRILLO DE LA ROSA, Yesid, Temas y problemas de la filosofía del derecho. Ediciones Doctrina y ley, Bogotá D.C., 2008, HARTH. el concepto de derecho, Traducción de Genaro R. Carrió, Buenos Aires: Abeledo - Perrot, 2004. 
funciones básicas: de cambio, de adjudicación y de reconocimiento ${ }^{32}$.

Las reglas de cambio permiten la adaptación de las normas jurídicas a la realidad social, pues en ellas se indica el procedimiento que permite conocer cómo pueden eliminarse, derogarse o introducirse nuevas reglas primarias al sistema jurídico.

Las reglas de adjudicación permiten fundar de manera incuestionable un juicio que establezca cuándo una regla primaria ha sido violada, o no, y aplicar la sanción instituida ${ }^{33}$.

La regla de reconocimiento, que cumple el papel de norma fundamental, garantiza la unidad del sistema y criterio último de validez, a partir del cual podemos identificar y reconocer una norma como válida dentro del sistema jurídico ${ }^{34}$.

La regla de reconocimiento de Hart no es presupuesta como en Kelsen, sino que forma parte del ordenamiento jurídico, no es un presupuesto o una ficción, es un hecho que puede asumir las formas más diversas, entre ellas; la referencia a un texto revestido de autoridad; a una sanción legislativa; a una práctica consuetudinaria; a las declaraciones generales de personas especificas; 0 a decisiones judiciales pasadas, dictadas en casos particulares. En los sistemas jurídicos modernos la regla de reconocimiento es más compleja porque no es sólo un hecho, también es una regla consuetudinaria que se expresa en una práctica convergente. Es un acto que puede advertirse desde un punto de vista externo y expresarse en enunciados externos, tal y como lo haría un observador que no se siente vinculado ni obligado por ella (ejemplo: "en Colombia el derecho dispone que...") y, es derecho, porque desde un punto de vista interno es reconocida y aplicada en la práctica por los tribunales y los funcionarios que utilizan los criterios previstos en ella para identificar el derecho y apreciar críticamente las desviaciones propias y ajenas; estos tribunales al referirse a ella utilizan un lenguaje que se expresa con enunciados internos, tal y como sucede con quienes aceptan

32 Ibídem

33 Ibídem.

34 Ibídem. la regla de reconocimiento ( Ejemplo: "El derecho dispone que.... $)^{35}$.

En opinión de Boaventura de Sousa Santos, una concepción no reducida del derecho y de la idea de una pluralidad de ordenamientos jurídicos, que coexisten en formas diferentes en las sociedades contemporáneas, compensa las precariedades analíticas de una estrategia política y cultural dirigida a revelar el pleno alcance de la regulación social que el derecho moderno hace posible y que en otro tiempo fue minimizado al Derecho estatal, así como el potencial emancipatorio del Derecho, una vez éste sea reconceptualizado.

Esto significa para Boaventura de Sousa Santos que, en abstracto, no existe nada progresista en la idea de la pluralidad jurídica. Lo mismo se aplica a los diferentes componentes estructurales del Derecho, exclusivamente a la retórica, ello para decir que el contenido progresista de la retórica se encuentra sujeta a la naturaleza de la audiencia retórica, de los tipos de topoi, distribución social de los argumentos razonables, relación entre persuasión y convicción, orden de los argumentos infiltrados por la burocracia y la violencia, entre otros. A ello suma la concepción de una pluralidad de ordenamientos jurídicos, propuesta la cual se intenta contrarrestar el prejuicio romántico de gran parte del pensamiento jurídico pluralista, en tal seguimiento observa la reconstrucción teórica del campo jurídico para sortear la igualación de todos los ordenamientos jurídicos en una unidad geopolítica y privativamente, negando la centralidad del derecho estatal en las formaciones sociojurídicas modernas ${ }^{36}$.

Finalmente asevera BOAVENTURA DE SOUSA SANTOS, sin desconocer las inadecuaciones y obscuridades, que el pluralismo jurídico ha sido objeto de debates centrales de la sociología del derecho y de la antropología del derecho. Establece la existencia de cuatro condiciones metateóricas, en que un tema se convierte en un debate central: (i) ser el tema muy amplio e inherentemente flexible que permita incluir en él nuevas dimensiones a medida que se desarrolla el debate. Igualmente, (ii) el tema debe tener límites

35 YESID CARRILLO DE LA ROSA "La inclusión de la moral en el derecho y la encrucijada actual del positivismo jurídico, revista Diálogos de Saberes, nro. 31, julio - diciembre de 2009, Bogotá. Universidad Libre, páginas 214- 217.

36 DE SOUSA SANTOS BOAVENTURA “ La Globalización del Derecho" Ilsa, 2002.página 19 -37. 
vagos, de forma tal que lo concerniente al debate no esté nunca muy claro. Sin embargo, (iii) saber lo que se debate es parte del debate en el campo de la sociología, un tema de tal naturaleza debe facilitar el vínculo macro - micro de articulación fácil entre el trabajo empírico y el desarrollo teórico. Por último, (iv) a través del tema debe ser posible abrir un debate entre discusiones centrales de otras disciplinas, siempre que la disciplina en cuestión consiga mantener su identidad en debates interdisciplinarios e incluso transdisciplinarios ${ }^{37}$

Respecto al positivismo, CORREAS indica que la ideología que tomó de Hume la convicción de que la certeza estaba ligada a la experiencia sensible, campea en los ámbitos universitarios. Ve en la verificación empírica ser una práctica recomendable, al menos en un mundo donde la eficacia es fundamental. Además cierto positivismo que se expresa sin importar los límites de verificación absoluta transformando la ciencia en un fetiche; en otras palabras, un ídolo creado por los hombres, se muda en algo insólito que oprime a su creador.

Observa CORREAS que los analíticos se deslumbran por la labor de los científicos duros, bajo la presunción que su cometido era convertir todo conocimiento, respecto del hombre, en discurso empírico pero verificable; cuestionando la producción no referenciada por la experiencia, dejada a la metafísica, a la sinrazón, a la calidad de pseudoproblema. Tendencia del avance contemporáneo de la Teoría del Derecho, pero bajo la guardia de terceros defensores de verificar en absoluto, la "pretérita" forma de hacer Filosofía. Calificando estos representantes del pasado analítico: "fetiches de la ciencia jurídica, de la dogmática y de la certeza" ${ }^{38}$.

Justifica el tema del verificacionismo absoluto ser la certeza y garantía de la objetividad. Capta una obsesión en cuidar las condiciones de verdad de los enunciados donde la garantía se encuentra en la verificación empírica, dando lugar a la claridad. Situación que considera empañarse cuando se trata del sentido. De allí que, para él, en los pensadores de dicha clase de analítica, la cuestión, respecto del discurso jurídico,

37Ibídem

38 CORREA OSCAR, "Metodología Jurídica I Una introducción filosófica" Editorial: Fontamara (México),2007. pretende aproximar el sentido a las cosas, es decir, garantizar que lo referido respecto del contenido de una norma sea tal, manifiestamente verdadero, como lo afirmado acerca de las pruebas que se realizan observando el comportamiento de los delfines.

En el fondo de lo dicho, para CORREAS existe un problema político importante. La idea de que del Derecho es factible expresar cosas irrefutables, la ciencia jurídica puede - y debe - arribar a la certeza acerca de su objeto, lo que conviene a quien tiene el poder - en otra mirada, señala, quien da el sentido, produce el discurso y tiene el poder de hacerlo -, le interesa que el sometido llegue a la convicción de la existencia de una ciencia que, irrefutablemente, indique con certeza qué debe y qué no debe hacerse. Esto, agrega, logra formar una pléyade de juristas quienes, coinciden por lo general con lo que el poder quiere, en otras palabras, quien lo consigue, tiene el poder ${ }^{39}$.

Asevera CORREAS ${ }^{40}$ que quien no dispone del poder, tiene otra convicción. Sabe que lo que el poder quiere es lo que le conviene, su Derecho es el que le favorece, hay un grupo de individuos que se ocupan de hacer saber exactamente qué es lo que el poder quiere. En este acto hay una interpretación, no ser exactamente lo que el poder pretende, y saber que este conocimiento le es perjudicial; desconociéndolo como un conocimiento científico, ello bajo el supuesto de ser un conocimiento "imparcial", "objetivo". Agrega, respecto de lo dicho, que lo conveniente es refutar la cientificidad del conocimiento del Derecho; con ello, así, disputa el poder o parte de él. Finalmente, predica, a veces es conveniente decir que el resultado de esa "ciencia" es incorrecto; que es "ideología", por tanto, se propone otra interpretación que hace difícil hablar de cientificidad cuando estamos ante un fenómeno político.

Por otra parte, admite que cuando un sector dominado logra arrebatar al poderoso un texto, que favorece al primero, conviene que no se "tergiverse" el texto, que se interprete siempre a favor de sus intereses. Y, en tal caso, le es favorable sustentar que el sentido es uno, y que la ciencia sí lo puede descubrir. Pero puede ser que los "científicos" empiecen a decir que el texto

39 Ibídem

40 Ibídem. 
debe interpretarse en sentido diverso, dando la posibilidad que se aplique la ley en perjuicio del sector a quien favorece al principio.

Avizora CORREA, que la cuestión de si conviene o no sostener que hay una interpretación "correcta" de la ley, depende de cuál ley se trate y de cuál sea el sector social que requiere sostener una posición al respecto. Afirmando que, si pretendemos vivir en un mundo democrático, se debe sostener que la interpretación correcta de los textos será la que consiga mayor democracia: Si se procura ser parte de un mundo más igualitario, se requiere sostener que la interpretación correcta, será la que consiga un mayor bienestar para la mayoría de la población. Y si se logra convencer a los juristas de que ésa debe ser su posición, se tiene ganada gran parte de la batalla.

Concluye, afirmando, que "el positivismo jurídico de corte analítico, le ha apostado a la posibilidad de la interpretación científica correcta, mientras a la Hermenéutica le queda hablar de la interpretación conveniente conforme con ciertas pautas éticas" ${ }^{41}$.

Mauricio García Rojas y María Paula Saffon, en un pronunciamiento en el artículo "Un siglo de crítica Jurídica"42, suman la siguiente disertación:

Las normas jurídicas y quienes las crean pueden ser objeto tanto de veneración como de aborrecimiento, e incluso originar guerras o consensos perdurables. Las Visiones del derecho, sus teorías, explicaciones o justificaciones, reflejan este carácter ambivalente y controvertible de lo jurídico. De allí surgen dos miradas opuestas. Una pone el acento en el papel estabilizador, regulador y hasta racional de las normas. La otra, en cambio, ve en ellas un arma de dominación en manos de quienes detentan el poder político. Las primeras visiones son más frecuentes e influyentes; no sólo predominan en las facultades de derecho sino en el ámbito judicial y en la administración pública. Las segundas, las visiones críticas, suelen ser vistas como marginales y tienen una influencia limitada ${ }^{43}$.

41 CORREA OSCAR, "Metodología Jurídica I Una introducción filosófica" Editorial: Fontamara (México),2007.

42 Mauricio García Rojas y María Paula Saffon" Un siglo de critica comparada" Universidad Nacional de Colombia, 2011.

43 Ibídem.
Durante el último siglo, agregan a lo dicho, en la historia de Occidente existieron un par de momentos en que las visiones críticas alcanzaron una acogida relativamente importante, no menos en las facultades de derecho. El primero durante las tres décadas iniciales del siglo XX en Europa y Estados Unidos. La industrialización, la urbanización y el auge de la modernización detonando grandes tensiones sociales, lo que dejó en evidencia la incapacidad del Estado para afrontarlas. Como consecuencia se causaron las grandes revoluciones sociales de Rusia y México. Le adicionan el estallido de la primera guerra mundial, la crisis económica y la incertidumbre sobre el funcionamiento del sistema internacional y la paz mundial. Agregan también las visiones europeas que logran cierto eco en América Latina, en donde fueron utilizadas por académicos que, no basta decir, defendieron la función social de la propiedad en países como Brasil y Colombia ${ }^{44}$.

Quienes haya estudiado derecho en la tradición civilista, en América Latina o en Europa continental, no puede menos que sorprenderse con la cantidad de análisis interdisciplinarios que existen en Estados Unidos sobre la materia. A diferencia de lo que suele suceder en Francia o en Argentina, por ejemplo, allí las miradas no dogmáticas del derecho son algo natural y frecuente, incluso entre quienes se interesan por la técnica jurídica y por el razonamiento estrictamente jurídico. En Europa, en cambio, a pesar de una conspicua tradición sociojurídica y de importantes desarrollos durante las dos últimas décadas, las miradas sociales del derecho mantienen una posición relativamente marginal, tanto en los ámbitos jurídicos como en los sociológicos (Dezalay, 1989) En América Latina, excepción hecha de algunos casos aislados en Brasil y Colombia, los estudios que abordan temas jurídicos desde otras ciencias sociales no sólo son muy escasos sino que hacen parte de un limbo olvidado entre ellas y el derecho. Entre otros ${ }^{45}$.

\section{EL PLURALISMO JURÍDICO EN PERSPECTIVA DE AUTORES COLOMBIANOS.}

Sin preámbulos se trascriben las conclusiones, como aporte a la teoría del pluralismo jurídico en el marco de la sociología jurídica o del derecho, 
sentadas por GONZALO CASTAÑO, OSCAR CORREA, ROGER COTTERREL, MAURICIO GARCÍA VILLEGAS, JAIME GIRALDO ÁNGEL, VÍCTOR MANUEL MONCAYO, GERMÁN PALACIO, JULIO ROMERO SOTO, RAMÓN SORIANO en torno a la sociología.

La sociedad genera un impacto que crea derecho. Significa que históricamente el derecho es una consecuencia de la sociedad y como tal ha cambiado a lo largo de su existencia; Colombia no ha sido la excepción, los diferentes autores relatan los cambios que se han producido en los últimos tiempos que han favorecido la sociología del derecho como ciencia. El derecho define el comportamiento social. De igual forma como la sociedad ha creado derecho, el derecho ha moldeado la sociedad, imponiendo normas mayoritariamente provenientes del Estado; pero tales normas principalmente son prohibiciones, en tanto que las normas que a sociedad ha impuesto son de orden comportamental, que a su vez han generado cambios en los ordenamientos jurídicos existentes.

En Colombia la pluralidad social ha generado una pluralidad jurídica. Una sociedad multiétnica y plural ha causado un impacto jurídico positivo toda vez que gracias a ello convergen variables que han permitido una diversidad normativa que ampara de manera efectiva las diferencias de género o culturales que cohabitan.

La sociología del derecho estudia las causas y los efectos de las normas. Este estudio busca entender el rol de la sociedad en el derecho, cómo esta crea derecho, pero a su vez es su destinataria; también el rol del derecho en la sociedad como con sus normas generan efectos en la sociedad y cambios en la misma.

Sociedad y derecho cambian de manera incesante. Al ser el derecho causa y efecto de la sociedad, cambia, en algunos casos en la misma medida que esta, en otros de manera anacrónica, pero siempre cambia para estar a tono con la sociedad a la que pertenece; de igual forma la sociedad cambia y altera sus comportamientos con las normas que impone el derecho, en una simbiosis cíclica ${ }^{46}$.

46 NANCY SOLANO DE JINETE Y OVER HUMBERTO SERRANO SUÁREZ " Redescubriendo la sociología del Derecho bajo la óptica de autores colombianos" Revista Misión Jurídica, número 3 enero- diciembre de 2010, Universidad Colegio Mayor de Cundinamarca p 252 y 253.
Aduce WILLIAM JIMÉNEZ GIL en su trabajo "Entre reglas y principios" ${ }^{47}$ que el analizar cada una de las características que se han predicado de los principios, se concluye obvio que tal tipo de normas refleja de manera mucho más cercana los presupuestos de la institucionalidad y de la vida social; en otras palabras, las reglas en clave de principios están mucho más cercanas del ideal de justicia que pretende el Derecho. Es decir, son unos instrumentos de solución de los conflictos sociales más dinámicos, si se quiere contemporáneos, frente a la vertiginosa y cambiante realidad que se afronta. Considera un imperativo revalorizar la aplicación de normas por vía de los principios, con la seriedad que demanda una tópica jurídica orientada a una hermenéutica principialista; pero, advierte, es fundamental y oportuno que se cambie el pensamiento conservador y anacrónico que reduce el Derecho a la ley y, para ello, entender que la noción de Derecho pasa por las realidades empíricas y se ubica mucho más cerca de una visión problematizante del Derecho que de una visión dogmática ${ }^{48}$.

Siguiendo a ROBERT ALEXY, conforme a su obra "Teoría de los Derechos fundamentales"49, encontramos la siguiente tesis: El debate actual de la distinción entre reglas y principios, se cavila, es un problema exclusivo del Derecho constitucional, equidistante en la interpretación de los Derechos fundamentales, aseverando que la distinción constituye el marco de una teoría normativo - material de los Derechos fundamentales, resultando ser punto de partida para responder a la pregunta acerca de la posibilidad y los límites de la racionalidad en la esfera de los Derechos fundamentales. Sin embargo, advierte, que el nacimiento del estudio del origen de la distinción entre reglas y principios, se observa en el Derecho privado y estará mucho más cercana al enfrentamiento entre el Derecho natural y el Derecho positivo ${ }^{50}$.

47 WILLIAM JIMÉNEZ GIL "Entre reglas y principios" Revista Misión Jurídica, número 1 enero- diciembre de 2008, Universidad Colegio Mayor de Cundinamarca" página 45.

48 Ibídem.

49 ROBERT ALEXY "Teoría de los derechos fundamentales" Centro de Estudios Constitucionales, Madrid 1993.

50 Ibidem página 19. 
"Para Dworkin, en el Derecho, además de las reglas, aparecen otro tipo de normas, que si bien están orientadas a determinadas decisiones sobre la obligación jurídica en circunstancias determinadas, operan de forma diferente. Su origen "no se basa en un decisión particular de ningún tribunal u órgano legislativo, sino en un sentido de convivencia $\mathrm{u}$ oportunidad que, tanto en el foro como en la sociedad, se desarrolla con el tiempo" en su obra (los derechos en serio) ${ }^{51}$. En el Derecho no solo hay normas, sino también algo lógicamente distinto, "los principios". Descubrir que un "principio" es un principio jurídico no es un ejercicio que se agote en la constatación sociológica o histórica acerca de los comportamientos observados en una determinada sociedad por parte de sus operadores jurídicos, sino que supone el desarrollo de una argumentación justificadora. En este sentido, los principios operan en el campo de la justificación o argumentación y no en el campo del descubrimiento o descripción del Derecho vigente" 52 .

En tal orden, establece que "Los "principios" entendidos en términos de Dworkin son estándares que requieren ser observados no en razón de favorecer o aseguran una situación económica, política o social que se piensa deseable, sino resultan ser una exigencia de la justicia, la equidad o alguna otra dimensión de la moralidad. Ello para implicar que la "directriz", o "directriz política", es un tipo de estándar que propone un objetivo que ha de ser alcanzado, bien sea una mejora en algún rasgo económico, político o social de la comunidad ${ }^{53}$.

Por su parte Martínez señala que, a partir de la expedición de la Constitución de 1991, surge una verdadera explosión jurídica que irradia a amplios sectores de la sociedad, sin embargo no resultaría de gran importancia si el alcance de esta explosión no captara cada día la atención de las organizaciones sociales, el pensamiento crítico $\mathrm{y}$, en cierta medida, conduciendo el devenir de la historia reciente ${ }^{54}$.

51 RONALD DWORKIN “Los derechos en serio" Ariel, 1984. 52WILLIAM JIMÉNEZ GIL, Op cit. página 30.

53 Ibídem, página 31.

54 JOSÉ EDUARDO RODRÍGUEZ MARTÍNEZ "Estado, Derecho y Justicia en Colombia: Aportes para un análisis desde la sociología jurídica crítica" en "De crisis en crisis: limitaciones de los cambios a la justicia en Colombia" Universidad Autónoma de Colombia, año 2012, página 14.
(...) no sólo se ha producido un proceso de pérdida de sistematización de los ordenamientos jurídicos y una crisis del Estado de derecho positivo sino que, además, se están gestando nuevos y más complejos conflictos, hoy asociados sobre todo con el medio ambiente y los derechos que reclaman, de un lado, las potentes industrias extractivas $y$, de otro lado, las poblaciones y actores sociales que sufren las consecuencias de la explotación ambiental ${ }^{55}$.

Comenta MARTÍNEZ que, constantemente, se ha sentenciado que el orden jurídico resulta ser el que más tardíamente reacciona a los cambios de la sociedad. No obstante en la actualidad es factible indicar que, a pesar de la tendencia todavía dominante del viejo Derecho, vive un proceso relativamente acelerado de edificación de un orden jurídico más afín a las realidades productivas y sociales, e incluso más punitivo en relación con el control social y la producción de la vida que reclama la sociedad contemporánea. Tal situación, no vacila constituir un verdadero campo de tensión y de contradicciones que muestra la crisis por la que atraviesa el Derecho en el presente ${ }^{56}$.

En la misma obra afirma que el modelo del positivismo jurídico, vigente casi todo el siglo $\mathrm{XX}$, se derrumba en forma vertiginosa dada la instauración del capitalismo globalizado. Observa que los fenómenos asociados con la aparición de las nuevas tecnologías, desterritorialización de la producción, pérdida de la soberanía del Estado nación, difusión de múltiples fuentes de producción del derecho, etc., invitan a pensar en la imposibilidad de que en términos de ordenamiento legal presente se arraiguen en un nuevo derecho desde la perspectiva positivista y Kelseniana.

La sociología jurídica viene cobrando cada vez más fuerza en los medios políticos y académicos, en parte debido a lo que, a nuestro juicio, está asociado con el agotamiento del modelo jurídico positivista dominante durante casi todo el siglo XX. Dicho agotamiento se alimenta de las recurrentes crisis de legitimidad de los sistemas jurídicos positivistas, del devenir estrictamente formalista del mismo, de los excesos de la casuística y su impacto en la descodificación y la sistematización que pretendieron las codificaciones, entre otros,

55 Ibídem páginas 14 y 15.

56 MARTINEZ, Op cit., $p 36$ y 51 . 
entre otros asuntos. Podríamos afirmar sin temor a equivocarnos que aunque los ordenamientos jurídicos positivistas cumplieron el importante papel de dotar a la sociedad de criterios de racionalidad esenciales a la regulación social $\mathrm{y}$, particularmente, fueron valiosos ene l campo de la juridización de las relaciones sociales durante el siglo XX, las dinámicas y realidades de la sociedad red, propia del mundo de la globalización y de las llamadas sociedades complejas o de la sociedad del conocimiento, reclaman incesantemente el desarrollo de un nuevo paradigma que enfrente los dilemas que se vienen produciendo por la crisis sistémica contemporáneas ${ }^{57}$.

Asegura MARTÍNEZ que el nombre de "pluralismo jurídico" goza de una connotación en forma definitiva normativa, en razón de que cualquier cosa que sea invocada con ese nombre, entiéndase buena por ser pluralista o, en su defecto, mejor que lo que sea opuesto como no pluralista. Esta connotación puede ser una fuente de error y, por tanto, debe ser evitada. En su opinión, no hay nada inherentemente bueno, progresista o emancipatorio acerca del "pluralismo jurídico". De facto, existen patrones de pluralismo jurídico que resultan bastantes reaccionarios. Por esta razón, prefiere hablar de una pluralidad de ordenamientos jurídicos, en lugar de pluralismos jurídico, cuando aspira reafirmar el tema asociado tradicionalmente con la última expresión ${ }^{58}$.

Predica atendiendo a EHRLICH, BOBBIO y DEL VECCHIO ${ }^{59}$ que la inadecuación del "pluralismo jurídico" puede ser escudriñada desde sus orígenes como concepto científico, para decir que surgió durante el cambio del siglo pasado al presente en la filosofía jurídica antipositivista, como renuencia contra la reducción del Derecho al derecho estatal, implementada por el movimiento codificador y desarrollado por el positivismo jurídico ${ }^{60}$, dejando claro, que es una reacción contra el centralismo o el exclusivismo estatal, instituida bajo el argumento que el derecho estatal

57 Ibídem página 51.

58 JOSÉ EDUARDO RODRÍGUEZ MARTÍNEZ "Estado, Derecho y Justicia en Colombia: Aportes para un análisis desde la sociología jurídica crítica" en "De crisis en crisis: limitaciones de los cambios a la justicia en Colombia" Universidad Autónoma de Colombia, año 2012, página 14 y ss.

59 Ibídem.

60 Ehrlich,1936;Bobbio,1942; Del Vecchio, 1957; Carbonnier, 1979. estaba, en realidad, distante de ser exclusivo y en ciertos momentos, no era central en la ordenación normativa de la vida social.

Igualmente indica MARTÍNEZ que, al mirar la vida sociojurídica en las sociedades europeas de la época del movimiento codificador, se detecta que la reducción del Derecho al derecho estatal era el resultado de un credo político donde la realidad empírica se aliaba con los "pluralistas jurídicos". Advierte que con la consolidación y la expansión del Estado constitucional liberal, y con la conversión de las hipótesis jurídicas positivistas en tesis hegemónicas (de sentido común) sobre el derecho, el centralismo o exclusivismo jurídico estatal se eclipsó como tal y pasó a ser el derecho tout court. Ello implico para los pluralistas jurídicos llevar la carga de la prueba al definir el Derecho como algo diferente al derecho estatal. Además, observa MARTINEZ ${ }^{61}$, cuando el positivismo jurídico sumó cierta sustancia analítica a su orientación política inicial, las tesis del pluralismo jurídico se percibieron mezcladas en un debate político sobre la definición del derecho.

MARTÍNEZ $^{62}$, siguiendo a NADER, HOOKER $\mathrm{y}$ otros, muestra que dicha mixtura de consideraciones analíticas y políticas, se ha desplegado en forma silenciosa, en no menos de los casos, cuando el pluralismo jurídico se tornó en un debate central en la sociología y la antropología del derecho, a partir de los años sesenta. ${ }^{63}$ Debido al positivismo científico que dominó estas disciplinas, observa, concederse predominio absoluto a las tesis analíticas del pluralismo jurídico, entre tanto las tesis políticas fueron erradicadas. En un giro curioso, afirma, el positivismo científico enfrentó al pluralismo jurídico neutralizando las tesis políticas de éste, aduciendo tesis alternativas no obstante ser igualmente políticas, resultaba factible defender con sentido convincente, analítico, particularmente en un contexto político en el que

61 JOSÉ EDUARDO RODRÍGUEZ MARTÍNEZ "Estado, Derecho y Justicia en Colombia: Aportes para un análisis desde la sociología jurídica crítica" en "De crisis en crisis: limitaciones de los cambios a la justicia en Colombia" Universidad Autónoma de Colombia, año 2012, página 14 y ss.

62 Ibídem.

63 Véase, entre otros, Nader, 1969, Hooker, 1975, Moore, 1978, Galanter, 1981; Macaulay 1983; Fitzpatrick, 1983; Griffiths, 1986; Merry, 1988; Starr y Collier, 1989; Chiba, 1989; Benda Beckmann, 1988, 1991; Tamanaha, 1993. 
el positivismo jurídico se hallaba en situación de debilidad extrema, en otras palabras en el contexto de las sociedades coloniales y poscoloniales. Todo para decir que el hecho de que éste complejo entrelazamiento de las tesis analíticas y políticas fuera escasamente reconocido, ha oscurecido el debate hasta nuestros días ${ }^{64}$.

Carlos Arturo Hernández, da a conocer en el marco Principios y Fundamentos de la Inviabilidad ${ }^{65}$ que los académicos de la antropología y de la sociología del derecho pretenden fraccionar el pluralismo jurídico en dos campos conceptúales o áreas temáticas de investigación: Strong legal plulism o pluralismo jurídico fuerte o el pluralismo jurídico contemporáneo y el Weak legal pluralism o el pluralismo jurídico débil o el pluralismo jurídico clásico. Para comentar, respecto del último, que representa el "sistema pluralista - jurídico" que se desplegó en los espacios coloniales y/o postcoloniales, última idea que recibe mayor enfoque, visto en cierta forma como el que mayor efecto ha tenido en los países latinoamericanos, asiáticos y africanos. Es decir, los lugares donde se desarrollaron regímenes coloniales o transferencias de las prácticas jurídicas - normativas (or legal transplant or legal transfer) o algún tipo de imposición de sistemas jurídicos, distantes de la "realidad" social y de las necesidades particulares de los actores que forman tal espacio político ${ }^{66}$.

Considera que el pluralismo jurídico fuerte representa la etapa contemporánea de dicho fenómeno, que tiene que ver con las formas normativas manifestadas en los países desarrollados o primermundistas. El énfasis primordial de este término conceptual, en consideración de HERNÁNDEZ, son los códigos normativos diseñados por los grupos o campos sociales "semiautonómicos" predicados por Moore, códigos que interactúan en el contexto del estado moderno - democrático -liberal y el derecho estatal monista, bien en el centralismo jurídico, sin dilapidar su aparente autonomía normativa $^{67}$.

64 Véase Starr y Collier, 1989; Benda -Beckmann, 1991; Tamanaha, 1993.

65 CARLOS ARTURO HERNÁNDEZ "Arquetipo de pluralismo jurídico - Análisis de sus visiones" revista Verba Iuris no 27 enero - junio de 2012. Universidad Libre.

66 Ibídem.

67 CARLOS ARTURO HERNÁNDEZ "Arquetipo de pluralismo jurídico - Análisis de sus visiones" revista Verba Iuris no 27 enero - junio de 2012. Universidad Libre.
Trata CARLOS ARTURO HERNÁNDEZ "Sobre la imposibilidad" y el pluralismo jurídico para referir a un grupo del sistemas jurídico que interactúa en un espacio político y social, denominado Estado. Para indicar que es posible en el plano de lo transnacional una especie de pluralismo jurídico, siendo ello más evidente en la interacción y el conflicto en el plano de lo nacional. Recalcando que las concepciones clásicas y contemporáneas del pluralismo jurídico epistemológicamente resultan obstruidos, atendiendo que en su lógica monódica (en términos de Gottfried Wilhelm Leibniz $^{68}$ o en su constitución Luhmanniana la interacción internormativa o sistémica es un elemento al margen de la teoría. De otra laso explica que es viable encontrar distintos sistemas normativos en un mismo espacio jurídico político, no obstante la interacción entre estos es mínima y ninguno de ellos ejerce hegemonía discursiva sobre los otros; son los individuos o los actores sociales los que acceden a estos sistemas normativos, siguiendo a Menkis.

Considera que la definición es problemática, bajo el supuesto que hacer posible el pluralismo jurídico requiere de una forma implícita o explícita, con una lógica de poder que, en cierta medida, garantice la interacción o que cavile la realidad a través de la legitimación de los sistemas jurídicos céntricos y alternativos. Todo en razón de que la lógica de la conflictividad social, en su sentir, requiere una lucha por el poder o por el control hegemónico del discurso legitimador. 0 bien, acudiendo al desgatado argumento foucaultiano, las relaciones político sociales exigen una lucha por el poder y las formas de normalización social y control. No obstante, advierte, que la teoría sistémica no contempla dicha instancia normativa y procura una total autonomía de los sistemas normativos, aspirando superar el centralismo jurídico ${ }^{69}$.

\section{CONCLUSIONES}

1. Mientras el positivismo jurídico se fundamenta en normas de poder y Estado encaminadas a justificar los procesos de capitalismo e industrialización en América Latina surge la posibilidad que el proceso histórico se encamine por voluntad y bajo el control de

68 Seguir su obra de correspondencia y escritos en temas de filosofía y política 1666 -1701.

69 Ibídem página 159. 
las bases comunitarias a través del pluralismo jurídico.

2. El positivismo jurídico, cimentado en un arquetipo de la norma por la norma como deber ser, se hace frágil en los tiempos de hoy, mientras el pluralismo jurídico acoge la necesidad de la observación de la norma para la realización del Derecho y por lo tanto permite una apertura de discrecionalidad en lo político y cultural en su aplicación.

3. Seguir la teoría del positivismo jurídico implica asumir el derecho como dinámica circunscrita al ordenamiento jurídico, alejada del hecho social que acoge el pluralismo jurídico para dar importancia a lo antropocéntrico.

4. La estructura normativista del moderno Derecho positivo estatal se torna inane ante la exigencia de una América Latina y un universo complejo y dinámico de las actuales sociedades de masas, que se aprestan a paradigmas conforme a las dinámicas vigentes de producción del capital, lo que implica significativas contradicciones sociales, inestabilidades continuadas que se expresan en crisis de legitimidad, producción y aplicación de la justicia.

5. El pluralismo legal, faculta la descarga de diversos $y$ vastos grupos sociales institucionalizados, quienes expiden y emplean sus propias disposiciones normativas, conforme a intereses de clase, asociaciones, fundaciones educativas, etnias, ideologías, y sistemas políticos y culturales.

6. Considerar una crisis del positivismo jurídico, y la alzada de un pluralismo jurídico, da lugar a preguntarse si hay una interpretación "correcta" de la ley, siendo primordial revisar, de cuál ley se trata, además del sector social y el soporte de su posición al respecto. Esto que permite pensar y revisar lo referente a la democracia, lo igual, lo equitativo, lo justo, y demás valores y principios que informan de la sociedad en que nos encontramos.

7. Sera objeto de debate en América Latina y otras latitudes, si los académicos de la antropología y de la sociología del derecho pretenden fraccionar o fortalecer el pluralismo jurídico en dos campos conceptúales o áreas temáticas de investigación: pluralismo jurídico fuerte o el pluralismo jurídico contemporáneo y el pluralismo jurídico débil o el pluralismo jurídico clásico.

8. En criterio de autores conocedores el "sistema pluralista - jurídico", que se desplegó en los espacios coloniales y/o postcoloniales, en cuanto al pluralismo jurídico clásico, recibe mayor enfoque y efecto en los países latinoamericanos, asiáticos y africanos; es decir, allí donde se implementan regímenes coloniales o transferencias de las prácticas jurídicas normativas o sistemas jurídicos, tangenciales a la "realidad" social, intereses particulares de los actores que forman tal espacio político.

9. Conforme a la doctrina se vislumbra una tripleta de componentes que inquieta a los académicos de la Teoría del Derecho y de la Sociología Jurídica en el marco de la crisis del derecho y la justicia, a saber: la eficiencia del derecho; los asuntos pertenecientes a la órbita de la eficacia del mismo y la legitimación del derecho y de la democracia.

10. Se desprende de la lectura concretarse aún de hecho, referentes de pluralismo jurídico vistos como altamente reaccionarios, lo que implica acudir a una terminología que descansa en una pluralidad de ordenamientos jurídicos, en vez de pluralismo jurídico.

11. Los principios vistos como normas conforme a autores citados refleja los presupuestos de la institucionalidad y de la vida social en el entendido que las reglas en clave de principios están mucho más cercanas del ideal de justicia que pretende el Derecho. Es decir, son vistos por los expertos en el tema como instrumentos de solución de los conflictos sociales más dinámicos y contemporáneos, es decir que son herramienta esencial en temas de pluralismo jurídico.

12. Al paradigma crítico, que ayuda a estudiar y analizar la tensión entre el positivismo jurídico y el pluralismo jurídico, se le atribuye ausentarse de buscar estudiar la validez del sistema jurídico. Esto conlleva a que, diversos autores, pretendan encontrar respuesta a por qué en el Derecho irrumpe la negación del derecho, en la existencia de un infraderecho que en el seno de una misma sociedad observa diferentes formas jurídicas, o que el Derecho requiera permanentemente una 
forma de argumentación para poder solucionar los casos de conformidad a la ley.

13. Entre los autores referidos se considera que en Colombia la pluralidad social implica una pluralidad jurídica. A su vez es una sociedad multiétnica y plural que marca un impacto jurídico positivo en el cual convergen variables que autorizan diversidad normativa, que ampara de manera efectiva las diferencias de género o culturales que cohabitan.
14. La sociología del derecho estudia las causas y los efectos de las normas. Este estudio busca entender el rol de la sociedad en el derecho, cómo ésta crea derecho, pero a su vez es su destinataria; también el rol del derecho en la sociedad como con sus normas generan efectos en la sociedad y cambios en la misma lo que permite enriquecer el debate entre positivismo jurídico en visión de crisis y el pluralismo jurídico como alternativa altamente acogida en el Derecho.

\section{BIBLIOGRAFÍA}

- AUSTIN, JONN, "la delimitación del ámbito de la teoría del derecho". En:

- CASANOVAS, Pompeu y otros. El ámbito de lo jurídico, lecturas del pensamiento jurídico contemporáneo, editorial Crítica, 1994.

- BONIlla MONTENEGRO JULIÁN DARÍO “Los paradigmas en la teoría jurídica. Transformaciones acerca de la interpretación sobre lo que es el derecho". , Universidad Colegio Mayor de Cundinamarca Revista Misión jurídica, número 3 enero- diciembre de 2010.

- CARRILlO DE LA ROSA, Yesid. Temas y problemas de la filosofía del derecho. Ediciones Doctrina y Ley, Bogotá D C., 2008.

- CARRILLO DE LA ROSA, YESID, Temas y problemas de la filosofía del derecho. Ediciones Doctrina y ley, Bogotá D.C., 2008 SORIANO, Ramón. Compendio de teoría general del derecho, Ariel. Derecho, Barcelona, 2a edición, 1993, p. 122, y MARTÍNEZ ROLDÁN, Luis y otro. Curso de teoría del derecho y metodología jurídica, editorial Ariel, S.A 1994.

- CARRILLO DE LA ROSA YESID “La inclusión de la moral en el derecho y la encrucijada actual del positivismo jurídico, revista Diálogos de Saberes, Bogotá. Universidad Libre nro. 31, julio - diciembre de 2009.

- CORREA OSCAR, "Metodología Jurídica I Una introducción filosófica" Editorial:
Fontamara (México),2007.

- DE SOUSA SANTOS BOAVENTURA "La Globalización del Derecho" Ilsa, 2002

- DWORKIN Ronald. Los Derechos en Serio. Ed. Planeta. Madrid 1993.

- HART Herbert. El Concepto de Derecho. Abeledo Petrot. Buenos Aires. 1992

- HART. H. El concepto de derecho, Traducción de Genaro R. Carrió, Buenos Aires: Abeledo - Perrot, 2004.

- HERNÁNDEZ, CARLOS ARTURO “Arquetipo de pluralismo jurídico - Análisis de sus visiones" Universidad Libre. Revista Verba Iuris no 27 enero - junio de 2012.

- JIMÉNEZ GIL, WILLIAM "Entre reglas y principios" Universidad Colegio Mayor de Cundinamarca Revista Misión Jurídica, número 1 enero- diciembre de 2008.

- KELSEN, H "Teoría pura del derecho. Introducción a la ciencia del derecho". Novena edición, Traducción de Moisés Nilve, eudeba editorial universitaria de Buenos Aires, 1970.

- KELSEN, H. "Teoría pura del derecho". Grupo editorial Éxodo, México D. F., 2006.

- LÓPEZ MEDINA DIEGO EDUARDO “Teoría impura del derecho - La transformación de la cultura jurídica latinoamericana" Legis, tercera edición 2005.

- RODRÍGUEZ MARTÍNEZ JOSÉ EDUARDO "Estado, Derecho y Justicia en Colombia: 
Aportes para un análisis desde la sociología jurídica crítica" en "De crisis en crisis: limitaciones de los cambios a la justicia en Colombia" Universidad Autónoma de Colombia, año 2012.

- RODRIGUEZ MARTINEZ JOSÉ EDUARDO "Derecho, subjetividad y espacialidad: Aportes para una discusión". Revista Diálogos de Saberes, número 31, Universidad Libre julio - diciembre de 2009.

- SEGURA ORTEGA, MANUEL. "La racionalidad jurídica”. Madrid: editorial Tecnos, 1998.

- SOLANO DE JINETE NANCY Y OVER HUMBERTO SERRANO SUÁREZ "Redescubriendo la sociología del Derecho bajo la óptica de autores colombianos", Universidad Colegio Mayor de Cundinamarca Revista Misión Jurídica, número 3 enero- diciembre de 2010.

- WOLKMER ANTONIO CARLOS "Pluralismo Jurídico Fundamentos de una nueva cultura del Derecho" editorial MAD 2006, España.

- WOLKMER ANTONIO CARLOS" Pluralismo jurídico, movimiento sociales y prácticas alternativas", http://ilsa.org.co:81/ biblioteca/dwnlds / od / elotrdr007/ elotrdr007-02.pdf, El otro Derecho, numero 7 de 1991, Ilsa Bogotá. Página 31, consultado 11 de noviembre de 2014.

- WOLKMER ANTONIO CARLOS. Introducción al Pensamiento Jurídico Crítico. Ed. ILSA y Facultad de Derecho de la Universidad Autónoma de San Luis de Potosí. México 2006. 